\title{
Prosopagnosia: current perspectives
}

This article was published in the following Dove Press journal:

Eye and Brain

26 September 2016

Number of times this article has been viewed

\section{Sherryse L Corrow ${ }^{1,2}$ \\ Kirsten A Dalrymple ${ }^{3}$ Jason JS Barton ${ }^{1,2}$}

'Human Vision and Eye Movement Laboratory, Neurology Division, Department of Medicine, ${ }^{2}$ Department of Ophthalmology and Visual Science, University of British Columbia, Vancouver, Canada; ${ }^{3}$ Institute of Child Development, University of Minnesota, Minneapolis, MN, USA

Correspondence: Sherryse L Corrow Human Vision and Eye Movement Laboratory, UBC/VGH Eye Care Centre, 360A - 2550 Willow Street, Vancouver, British Columbia V5Z 3N9, Canada Tel +I 6048754 III ext 67672

Fax +l 6048754302

Email sherryse.corrow@icloud.com
Abstract: Prosopagnosia is a selective visual agnosia characterized by the inability to recognize the identity of faces. There are both acquired forms secondary to brain damage and developmental forms without obvious structural lesions. In this review, we first discuss the diagnosis of acquired and developmental prosopagnosia, and the challenges present in the latter case. Second, we discuss the evidence regarding the selectivity of the prosopagnosic defect, particularly in relation to the recognition of other objects, written words (another visual object category requiring high expertise), and voices. Third, we summarize recent findings about the structural and functional basis of prosopagnosia from studies using magnetic resonance imaging, functional magnetic resonance imaging, and event-related potentials. Finally, we discuss recent attempts at rehabilitation of face recognition in prosopagnosia.

Keywords: face recognition, perception, fusiform gyrus, anterior temporal, review

\section{Introduction}

Face recognition is usually effortless and rapid. In different places and times, despite changes in expression, hairstyle, and clothing, we easily recognize colleagues, friends, and family. Our visual expertise with faces likely exceeds that for any other type of object, and this ability to identify people is a cornerstone of our social interactions as human beings. Subjects with prosopagnosia, however, cannot recognize that they have seen a face before, an impairment that affects both faces well known to them and those recently encountered. This is not due to more general problems with vision, object recognition, or memory. The term "impaired face recognition" should be used rather than "prosopagnosia" when this symptom is part of a broader problem, as with macular degeneration, general memory problems in Alzheimer's disease, and cognitive issues in schizophrenia, for example. These subjects realize that a face is a face and not a car or a tree, but simply cannot say whether they have seen it before or whose face it is. These subjects rely on other cues to identity, such as hairstyle, gait, or voice, and make mistakes if these cues change (eg, hairstyle). They relate surprising and sometimes embarrassing stories, such as not recognizing themselves in a mirror, or walking past siblings or spouses as if they were strangers.

Prosopagnosia can be either acquired or developmental. In acquired prosopagnosia, poor face recognition is the result of brain injury. While the first case of acquired prosopagnosia was reported 150 years ago, ${ }^{1,2}$ the modern study of this condition began with Bodamer' ${ }^{3}$ report in 1947, which described impaired face recognition in wounded soldiers. Subsequently, it has been recognized that acquired prosopagnosia can arise 
from many different pathologies, including trauma, stroke, encephalitis, tumors, degenerative atrophy, or temporal lobe resections. $^{4}$

Developmental prosopagnosia has been more recently described and is less well understood. Subjects with this condition fail to develop face recognition skills despite otherwise normal vision and memory, and do not have obvious lesions on brain imaging. ${ }^{5,6}$ Developmental prosopagnosia may have a genetic basis. It can run in families, with some pedigrees showing as many as ten affected members across two generations, ${ }^{7-9}$ observations that parallel findings that normal face recognition skills also have a heritable component, with monozygotic twins having more similar face recognition abilities than dizygotic twins. ${ }^{10,11}$ While the acquired form is rare, the developmental form may be relatively common. Some suggest that as many as $2.5 \%$ of the population has developmental prosopagnosia, ${ }^{12,13}$ although this number will vary with the statistical criteria used and may confound those subjects with a developmental problem with those on the low end of normal face recognition ability (see Barton and Corrow $^{14}$ for a discussion on the prevalence and diagnosis of developmental prosopagnosia).

Prosopagnosia has significant implications for those who have it. Adults with developmental prosopagnosia often report that their failure to recognize others creates traumatic social experiences, leading to chronic anxiety, feelings of embarrassment and guilt, and a limited social circle. ${ }^{15}$ Our subjects with acquired prosopagnosia acknowledge similar difficulties. Children with developmental prosopagnosia and their parents describe the same problems, but with additional implications for the school environment and safety. ${ }^{16}$

\section{Models of face recognition}

Face recognition is a multistage process ending with the identification of a person. These stages are reflected in cognitive models of face recognition, the most influential being that of Bruce and Young ${ }^{17}$ (Figure 1). Each box in the model represents a distinct cognitive process: while it is not necessary that these different stages occur in separate anatomic structures, some neuroanatomic models suggest that this may be the case. ${ }^{4,18}$ The model begins with creating a "facial percept", the encoding of the structural information about the face. This percept is matched to stores of face memories, termed "face recognition units", to determine whether the face has been seen before. Some argue that a correct match at this stage produces a feeling of familiarity with the face. ${ }^{19-21} \mathrm{~A}$ correct match also activates a "person identity node", which

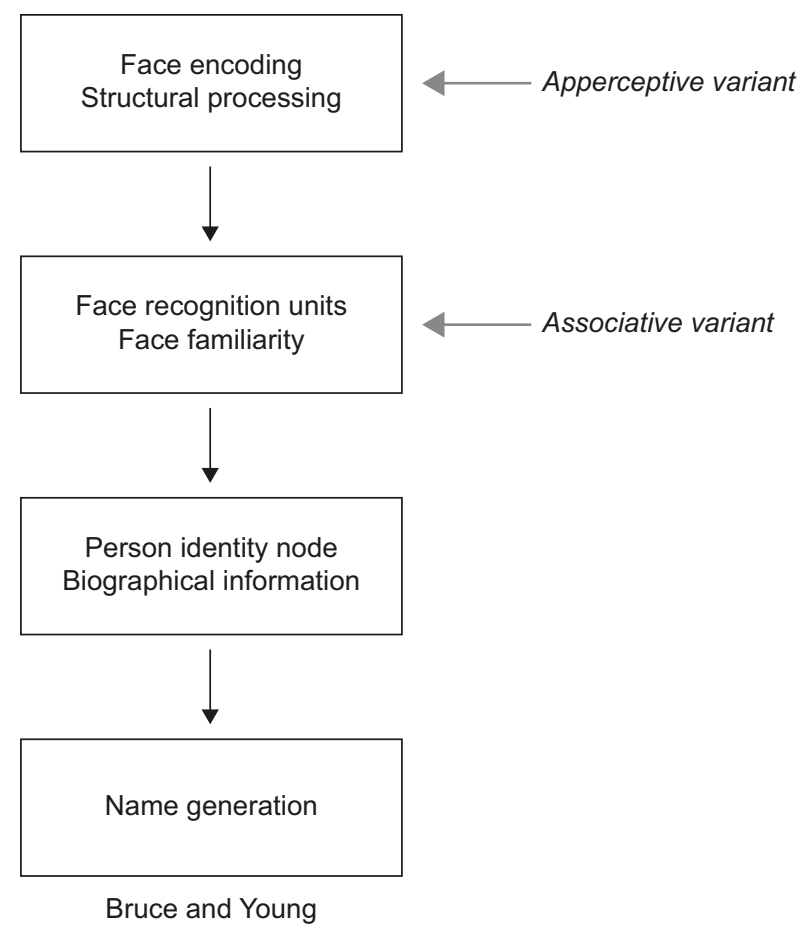

Figure I Adaption of the Bruce and Young model.

Notes: In the associative variant of prosopagnosia, face encoding is thought to be intact, represented by the ability to accurately discriminate between faces. However, faces are not seen as familiar suggesting a failure to activate face recognition units, subsequently affecting later stages in the face-processing stream. In the apperceptive variant, face encoding is thought to be impaired, affecting all later stages in the model when faces are the cue to identity. Gray arrows indicate the first stage of the model showing the greatest deficit in apperceptive and associative variants of prosopagnosia, respectively. (C)1986 The British Psychological Society. Adapted from Bruce $\mathrm{V}$, Young $\mathrm{A}$. Understanding face recognition. $\mathrm{Br} J$ Psychol. 1986;77(Pt 3):305-327 with permission John Wiley and Sons. ${ }^{17}$

allows access to semantic information and the name of the person to whom the face belongs. This model continues to be useful and has been elaborated to incorporate parallel sources of information from other cues (eg, voice), ${ }^{22,23}$ hemispheric lateralization of these cues, ${ }^{20}$ and more extensive bidirectional influences between modules. ${ }^{19,22-25}$

These models are reflected in our concepts about prosopagnosia. There are functional variants that may correspond to dysfunction of different cognitive stages. ${ }^{26}$ Impairments in the ability to see differences between faces, or their structures, suggest an "apperceptive variant", a failure in encoding the facial percept. Other prosopagnosic subjects can perceive facial structure accurately but on tests of facial imagery cannot recall the faces of familiar people, indicating an "associative or amnestic variant". However, this is a relative rather than absolute dichotomy: subtle defects in face perception can be seen in patients with an associative variant, ${ }^{27-30}$ while those with an apperceptive variant have milder deficits on face imagery tests. ${ }^{4}$ Nonetheless, this distinction remains useful, and these variants have distinct neural correlates (see "Neuroimaging" section). ${ }^{4}$ 


\section{Diagnosis \\ Tests of face familiarity}

The hallmark of prosopagnosia is the reduced ability of subjects to realize that they have seen a face before: hence, key diagnostic tests probe the sense of familiarity for previously seen faces. Earlier tests of face recognition may have been less sensitive because their stimuli could allow subjects to use alternative strategies to circumvent poor face recognition, such as remembering hairstyles and clothing. ${ }^{31,32}$ Newer tests have addressed those limitations by minimizing those extraneous cues. The most commonly used test of familiarity for recently viewed faces is the Cambridge Face Memory Test (CFMT), ${ }^{33}$ a test with high internal reliability. ${ }^{34}$ While the original version of this test used only adult Caucasian faces, other versions have been created, such as the CFMTChinese, ${ }^{35}$ CFMT-Australian, ${ }^{36}$ and pediatric versions, such as the CFMT-C ${ }^{37}$ and the CFMT-Kids. ${ }^{38}$

Tests that use anonymous faces like the CFMT have the advantage that, as none of the faces are familiar to subjects prior to learning, all subjects taking the test have the same degree of short-term familiarity with the faces seen during the test. Tests of familiarity for famous faces are also used, but such tests depend on the person having seen those celebrities before, and are therefore affected by age, education, and cultural background. In prosopagnosic subjects, this can be compounded by the fact that these subjects may lose interest in films and television because they cannot keep track of the characters, thus limiting their exposure to newer celebrities.

\section{Tests of face perception}

Tests of face perception - that is, the ability to perceive differences between faces - do not establish the diagnosis of prosopagnosia. What they can do is demonstrate if prosopagnosia is due to impaired encoding of the facial structure, and therefore is an apperceptive variant, or if such encoding is intact, which would point to an associative variant. Deficits in face perception have been measured by the Cambridge Face Perception Test ${ }^{39}$ and the Glasgow Face Matching Test, ${ }^{40}$ which involve sorting or matching faces by their identity with minimal demands on memory. The Dartmouth Face Perception Test is useful for children. ${ }^{41}$

\section{Questionnaires of social impact}

Questionnaires can evaluate everyday experiences with face recognition. There is a 15 -item self-report questionnaire ${ }^{13}$ that contains questions on face recognition, attractiveness judgments, and expression recognition, and a more recent 20-item questionnaire for face identity (Prosopagnosia Index,
"PI20", ${ }^{42}$. However, these should be supplemented by objective tests for diagnosis.

\section{Exclusionary tests}

Establishing impaired face recognition is not sufficient for the diagnosis of prosopagnosia. One must also show that this is not due to more general problems with vision and memory. The assessment of acuity and visual fields can exclude lowlevel impairments of vision as a cause of poor face recognition: indeed one of the problems of subjects with macular degeneration is difficulty recognizing faces. ${ }^{43}$ Beyond this, to exclude a more general visual agnosia, subjects with prosopagnosia should have normal object recognition at a "basic" level (ie, identifying that an object is a face, a bicycle, a lamp, etc). Some may have difficulties identifying specific examples of these objects (ie, which bicycle or which lamp): this is not grounds for rejecting a diagnosis of prosopagnosia, but is relevant to the debate about whether the recognition problem in prosopagnosia is truly specific for faces alone (see "Face Specificity" section). For this reason, challenging tests of object recognition that include measures of reaction time and premorbid expertise ${ }^{44}$ are useful (see "Objects" section).

Finally, face identity recognition deficits can occur in the context of other disorders, and the diagnostic process should consider whether any of these are present. In children, this includes conditions such as autism ${ }^{45-48}$ and Turner's syndrome,${ }^{49}$ while in adults impaired face recognition has been reported in schizophrenia, ${ }^{50,51}$ Alzheimer's disease, ${ }^{52-54}$ and Parkinson's disease, ${ }^{55}$ for example. The diagnosis of prosopagnosia should be reserved for cases in which poor face recognition cannot be explained by one of these other conditions. Suggested criteria for the diagnosis of acquired and developmental prosopagnosia are outlined in Table 1. Greater detail regarding guidelines and available tests can be found in a recent review. ${ }^{56}$

\section{Face specificity}

Are prosopagnosic subjects impaired in the recognition of faces only? Here, we comment on four aspects of this question about specificity. First, a long-standing debate in face research is whether the mechanisms used to process faces are dedicated to faces alone, ie, "face specific", or if they are involved in processing other objects, particularly those for which we possess perceptual expertise. ${ }^{57-59}$ Second, new theories have proposed that words and faces, two visual classes for which literate humans have great expertise, share and compete for resources, leading to predictions that prosopagnosic subjects may have subtle deficits in word 
Table I Suggested inclusion and exclusion criteria for the diagnosis of acquired and developmental prosopagnosia

\begin{tabular}{lll}
\hline Inclusion criteria & Exclusion criteria & Clarification questions \\
\hline - Difficulty with faces evident in everyday & - Low-level visual impairment that could & - Does the individual have associative or apperceptive \\
life (PI20) & otherwise explain prosopagnosia & subtype? (Cambridge Face Perception Test or \\
- Impairment on at least two measures of & - General visual agnosia & Glasgow Face Matching Test) \\
face familiarity (CFMT) & - General memory impairment & - Is the disorder prosopagnosia or a multimodal \\
- Confirmation of lesion by MRI or CT & - Neuropsychological disorders associated & person recognition disorder? (Tests of name and \\
scan (AP cases only) & with face recognition impairment & voice familiarity) \\
& - Visible lesion on MRI (DP cases only) & \\
\hline
\end{tabular}

Note: Suggested tests for adults are indicated in parentheses, and brackets indicate criteria specific to either acquired prosopagnosia (AP) or developmental prosopagnosia (DP).

Abbreviations: CFMT, Cambridge Face Memory Test; MRI, magnetic resonance imaging; CT, computed tomography.

processing..$^{60,61}$ Third, questions have arisen as to whether some prosopagnosic subjects may actually have a multimodal problem in recognizing people. ${ }^{19,62,63}$ If so, they should also have impairment of recognition of people by voice and name; however, voice recognition has seldom been objectively evaluated in prosopagnosia. Finally, an issue of less theoretical but some practical interest is the array of other visual deficits that likely reflect damage to neighboring structures and networks, particularly with acquired prosopagnosia.

\section{Objects}

All objects share visual processing in the striate and early extrastriate cortex: whether the processing of faces and objects diverges later is the question. Neuroimaging studies of healthy individuals show that face processing depends on a cortical network of regions that is partially overlapping but distinct from areas involved in object processing. ${ }^{64-67}$ Transcranial magnetic stimulation has demonstrated a double dissociation between face and object processing: stimulation of face areas interrupts face processing more than object processing and stimulation of object areas results in the reverse. ${ }^{68}$

The contribution of prosopagnosia research to this debate is mixed. While there are studies that report intact ability to distinguish between members of other object categories, ${ }^{28,69-76}$ others describe cases who have difficulty ${ }^{63,77}$ If prosopagnosia is about expert processing, though, a notable omission from many of these studies is the failure to consider the premorbid expertise of the prosopagnosic subject for the objects being used in the testing. A recent advance is the development of a method to use verbal semantic knowledge about a type of object as an index of their premorbid expertise and to adjust visual recognition scores for the degree of expertise. When this was done, nine of ten subjects with acquired prosopagnosia were impaired in expertise-adjusted car recognition. ${ }^{44,78}$

Similar mixed results have been obtained in adults with developmental prosopagnosia, with several studies describing cases in which the recognition deficit affected only faces $^{9,79-84}$ and some cases in which the recognition of other objects was also impaired. ${ }^{8,9,79,80,85-88}$ This is true for studies of children too. ${ }^{9,49,89-92} \mathrm{~A}$ study of six children with developmental prosopagnosia found face-specific deficits in four, and more general deficits for both faces and objects in one..$^{93}$ These differences across cases and studies may reflect a real heterogeneity rather than methodological issues.

One study has also attempted to evaluate the effect of object expertise on recognition ability in developmental prosopagnosia. ${ }^{34}$ Using the Cambridge Car Memory Test,${ }^{94}$ this study reported that, at the group level, those with developmental prosopagnosia did not differ from controls after controlling for car expertise. However, individual data were analyzed before controlling for expertise, making it difficult to know whether expertise-adjusted car recognition was intact in each subject.

\section{Words}

Next to faces, words may be the stimulus category for which we have the highest degree of visual expertise. Although face processing is more active in the right hemisphere and word processing on the left, both show bilateral networks that overlap. ${ }^{95} \mathrm{~A}$ recent theory proposes that face processing and word processing compete for neural resources during development and that incomplete hemispheric lateralization is a result of this competition. ${ }^{60,96,97}$ The prediction of this theory is that prosopagnosic subjects should have subtle impairments in the processing of words, even if their lesions are limited to the right hemisphere.

Several recent studies have tested this prediction in acquired prosopagnosia. One study found subtle impairments in word processing in three subjects, ${ }^{61}$ but these may have had a more general integrative visual agnosia rather than prosopagnosia. ${ }^{81,98} \mathrm{~A}$ second study of five subjects found normal performance on seven different reading tasks. ${ }^{99} \mathrm{~A}$ third study ${ }^{100}$ found that only prosopagnosic subjects with bilateral fusiform lesions showed an increased word-length effect (the time taken to read a word as a function of the number of letters), and slow sorting of printed cards by their word content. On the other hand, even subjects with right hemisphere lesions alone were impaired when they had to sort the same cards by their 
font or handwriting. This suggested that the right hemisphere makes a critical contribution to the processing of stylistic properties of written text, rather than analyzing their word content. However, a similar recent study in developmental prosopagnosia has not found any deficit in processing the words or style of writing. ${ }^{101}$ This may indicate that the styleprocessing impairments in acquired prosopagnosia are related to damage to adjacent processing areas rather than damage to the mechanisms involved in face processing.

\section{Voices}

Another question of specificity has examined whether individuals with prosopagnosia have difficulty in only the recognition of faces, or whether they struggle with person recognition more generally, such as the recognition of voices. On the other hand, years of relying on voice cues to recognize others may produce superior voice recognition in prosopagnosic subjects. ${ }^{102}$

A recent study of acquired prosopagnosia found that only subjects with bilateral anterior temporal lesions had deficits in the recognition of voices, and therefore were better classified as having a multimodal disorder of person recognition. ${ }^{62}$ However, the recognition deficit was specific to faces and did not involve voices or names in those with right anterior temporal lesions alone or occipitotemporal lesions. A second study of 12 subjects with developmental prosopagnosia found impaired voice recognition in only one subject; ${ }^{103}$ nevertheless, this provides more evidence for heterogeneity in the developmental variant.

\section{Other deficits from damage to adjacent structures}

The classic tetrad found with acquired prosopagnosia, particularly when due to occipitotemporal lesions, is superior field deficits, dyschromatopsia and topographic disorientation. Cerebral dyschromatopsia is associated with damage to the lingual and fusiform gyri, in the vicinity of the collateral sulcus, almost always with bilateral but rarely with right unilateral lesions. ${ }^{104,105}$ It is characterized primarily by an accentuation of the tritanopic-like patterns seen in healthy subjects. ${ }^{104}$ This last study did not find color impairments in subjects with developmental prosopagnosia.

Topographic disorientation, a disorder in which subjects get lost in familiar surroundings, is commonly reported with acquired prosopagnosia. A recent review found mention of topographic difficulty in $29 \%$ of 147 cases. ${ }^{106}$ One possible explanation is the close proximity of the parahippocampal place area, ${ }^{107}$ an area activated when viewing scenes, to the fusiform face area (FFA), ${ }^{108}$ which is activated by viewing faces. In developmental prosopagnosia, there are anecdotal reports of both impaired ${ }^{94-96,109}$ and preserved ${ }^{84,110,111}$ navigational abilities. A recent study found that most patients with acquired prosopagnosia, regardless of lesion location, were impaired in scene and landmark recognition, while those with occipitotemporal lesions were also impaired in the ability to form cognitive maps, ${ }^{112}$ and either deficit was rare in developmental prosopagnosia.

\section{Neuroimaging}

The advent of functional imaging has revolutionized cognitive brain science. In face research, it has delineated networks of regions active during face perception. This includes a core face network that includes the FFA, ${ }^{108}$ the occipital face area (OFA), and the posterior portion of the superior temporal sulcus $^{113,114}$ (Figure 2). There is also an extended network that includes the anterior temporal face area and other regions such as the inferior frontal gyrus and precuneus. ${ }^{4,115}$ While faces activate these areas in both hemispheres, ${ }^{95,114}$ the effect is stronger on the right. ${ }^{108}$

Studies of acquired prosopagnosia have been advanced by the improved functional and structural capabilities of magnetic resonance imaging (MRI). A key fact is that a variety of lesions can cause prosopagnosia, ${ }^{116}$ an observation that makes sense when one considers the widely distributed networks involved in face processing. Two key observations have been made from the study of acquired prosopagnosia. First, lesions may be bilateral or unilateral, and when unilateral they are far more likely to be on the right. ${ }^{4,117,118} \mathrm{~A}$ few prosopagnosic subjects with left-sided lesions have been described, but most have been left-handed, ${ }^{119-121}$ raising the possibility that they may have had anomalous hemispheric lateralization to begin with. Second, there is a useful division between occipitotemporal and anterior temporal damage. Recent functional MRI work has shown that occipitotemporal damage is associated with loss of activation of core components such as the FFA and OFA, ${ }^{78}$ while activation in anterior areas may be spared. ${ }^{122}$

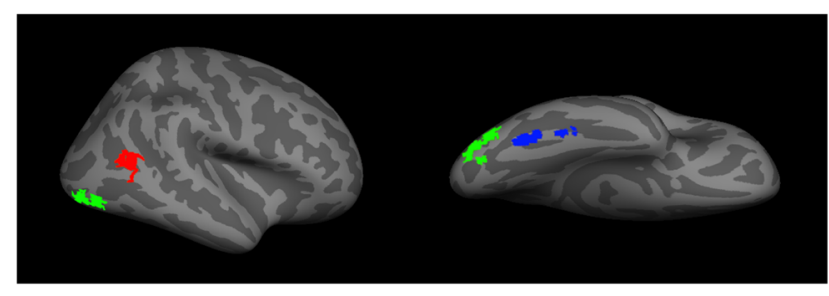

Figure $2 \mathrm{~A}$ representation of the core face network - including the fusiform face area (blue), the occipital face area (green), and the posterior superior temporal sulcus (red). 
Conversely, activation of the FFA and OFA may be spared in individuals with anterior temporal lesions. ${ }^{78}$

These modern neuroimaging observations have generated structural correlates for functional variants of prosopagnosia that had long been hypothesized (see "Models of face recognition" section and Figure 1). ${ }^{26}$ Recent studies show that those with fusiform lesions are more likely to have the apperceptive variant, ${ }^{4,78,123}$ whereas those with anterior temporal lesions are more likely to have the associative variant ${ }^{4,78,124,125}$ (Figure 3). The main conclusion is that acquired prosopagnosia is not a single disorder, but a family of disorders with different mechanisms and different lesions that nevertheless lead to the same end result of impaired face recognition. ${ }^{78}$

The structural correlates of developmental prosopagnosia are still debated. By definition, there is no obvious structural lesion, and early studies examining the evidence of abnormal activation of the core face network produced mixed results, with some reporting normal activation ${ }^{126,127}$ and another reporting activation for faces that did not differ from activation for other object types. ${ }^{126-128}$ Recent work with more advanced imaging methods has begun to uncover both structural and functional anomalies in developmental prosopagnosia, but there is disagreement. Some have suggested that there are anatomical $^{84}$ or functional ${ }^{129-131}$ abnormalities in the FFA and localized differences in white matter fibers around the right FFA. ${ }^{132,133}$ Others maintain that the core face network is largely normal and that abnormalities lie instead in the anterior temporal cortex, ${ }^{134,135}$ other regions of the extended face network, ${ }^{136}$ or the long-range white matter tracts that connect the core regions in occipitotemporal cortex with the anterior

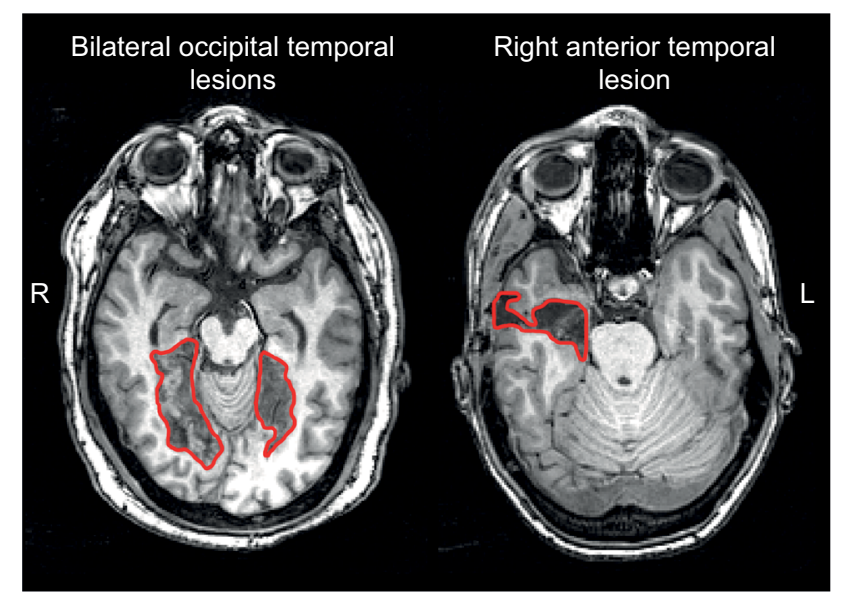

Figure 3 Examples of lesions that produce acquired prosopagnosia.

Notes: Approximate lesions, as can be seen on a single slice, are outlined in red. Patients with bilateral occipital temporal lesions (left) often experience apperceptive prosopagnosia and those with anterior temporal lesions (right) often experience associative prosopagnosia. These cases demonstrate that acquired prosopagnosia is a family of disorders with different mechanisms and different lesion locations that lead to the same end result of prosopagnosia. temporal face area, namely the inferior longitudinal fasciculus. ${ }^{134,137}$ Both groups claim that the degree of altered white matter connectivity in their results correlated with behavioral measures of impaired face recognition. ${ }^{133,137}$ Whether these discrepancies reflect a real heterogeneity that exists in developmental prosopagnosia remains to be determined.

\section{Event-related potentials}

While event-related potentials do not have as good spatial resolution as MRI, they have a much finer resolution in time and can advance our understanding of the temporal dynamics of face recognition. Studies of face recognition in healthy subjects identify three components. The N170 component is prominent in right lateral occipitotemporal areas: it shows larger responses to faces than other objects and is associated with perceptual aspects of face processing. ${ }^{138-140}$ The N250 is also right-dominant and is the first component to show effects linked to the appearance of a specific facial identity, rather than just faces in general. ${ }^{18,141,142}$ The P600 is seen when subjects can recognize a person by stating their name or providing information about them. ${ }^{142,143}$

Studies of acquired prosopagnosia support the association of the N170 with both an occipitotemporal location and perceptual aspects of face processing. Dalrymple et al ${ }^{144}$ found that the face-selective aspect in the N170 was absent in subjects with apperceptive prosopagnosia whose lesions included at least two components of the core network (eg, FFA and OFA). However, it was intact in those with associative prosopagnosia whose lesions were restricted to anterior temporal cortex. Another study supported this finding by demonstrating preserved N170 face-selectivity in a subject with a right OFA lesion but preserved right fusiform gyrus, ${ }^{145}$ and other studies reported its absence in a subject with impaired face perception. ${ }^{143,146}$

The findings in developmental prosopagnosia are less straightforward. ${ }^{139}$ There are reports of both normal ${ }^{147-149}$ and abnormal N170 components, ${ }^{111,129,147,150}$ including one on the analogous M170 component detected by magnetoencephalography. ${ }^{151}$ Larger studies have found heterogeneous results across subjects that can explain this inconsistency. ${ }^{147,152-154}$ It is also possible that there are more subtle abnormalities in the N170 component. For example, the amplitude of the N170 component is usually larger when viewing upside-down faces, likely because it is harder to process them, but one study found that the majority of 16 subjects with developmental prosopagnosia failed to show an orientation effect in the N170 amplitude. ${ }^{152}$

With regard to the later potentials, a study of 12 subjects with developmental prosopagnosia found normal N250 and 
P600 components on the few trials on which these subjects did identify a face, suggesting relatively normal processing when face recognition is successful. About half also exhibited N250 components for famous faces they did not recognize, which may indicate some unconscious processing. There was no P600 component under those circumstances, implying that this potential reflects conscious face identification. ${ }^{155}$ Even though these studies indicate that the processes indexed by these later potentials can still be activated in developmental prosopagnosia, a recent Event Related Potential study claimed that these components are delayed ${ }^{156}$ (see Towler et $\mathrm{al}^{157}$ for a recent review of ERP findings in developmental prosopagnosia).

\section{Treatment and rehabilitation}

Can training improve prosopagnosia? The answer may be that it depends. In acquired prosopagnosia, one might speculate that the efficacy of any training could be affected by age at onset, duration since onset, and lesion size, laterality, and location, particularly with regard to how much of the face network and its connections are compromised. ${ }^{158}$ Given the rarity of acquired prosopagnosia, it will be very difficult to establish the impact of each of these factors. To date, there have been few remedial attempts for the acquired variant, and most focus on enhancing coping strategies to circumvent poor face recognition. ${ }^{158,159}$ Only one published study attempted to improve face recognition, in a child with diffuse damage after meningococcal meningitis: 18 months of training did not improve matters. ${ }^{160}$ More recently, two training studies have been reported at conferences. DeGutis et al ${ }^{159,161}$ attempted to train a 46-year-old with a right occipital-temporal lesion to categorize faces based on the distances between face parts. Unfortunately, this did not help. A second study trained 12 subjects to discriminate increasingly subtler differences in face shape across variations in expression and viewpoint, over 11 weeks. Some improvement was found, but this was more modest for the recognition of faces not used during training. ${ }^{162}$

Given the lack of overt brain damage, one might wonder whether training may be more effective in developmental prosopagnosia. One group trained 25 subjects with developmental prosopagnosia ${ }^{163,164}$ to perceive the spacing between facial features and found improvements that generalized to new faces but did not help recognition when viewpoint varied. ${ }^{164} \mathrm{~A}$ different therapeutic approach was used in a randomized, placebo-controlled, double-blind study examining the effect of intranasal inhalation of oxytocin, a drug associated with the regulation of social behaviors, on face identity processing. ${ }^{165}$ The authors reported transient improvement of face perception and recognition in ten subjects with developmental prosopagnosia after oxytocin administration.

While these reports are encouraging, there may be limitations. Given the heterogeneity of deficits in prosopagnosia, it may be that a specific training program will not be appropriate for all subjects. How much of a residual face network one needs in acquired prosopagnosia to benefit from training is unknown. The belief that the subtler structural alterations of developmental prosopagnosia imply a better chance of having the neural substrate to generate benefit from training is unproven.

\section{Conclusion}

A prevailing theme in prosopagnosia research is the heterogeneity of findings across both acquired and developmental prosopagnosia. There is heterogeneity in the mechanism of prosopagnosia (ie, apperceptive versus associative), the location, lateralization, and extent of structural damage in the acquired form, and the presence or absence of impairments in other perceptual domains (eg, object, word, and voice processing). Heterogeneity is expected when one is dealing with a complex process such as person recognition, but it does create challenges that require particular care and rigor in experimental study and analysis.

For one, it is important to ensure that heterogeneity is not the inadvertent result of experimental factors. To this end, care is required in establishing the diagnosis of prosopagnosia and excluding other conditions (Table 1). First, besides excluding more general failures in object recognition and memory, tests of voice and name recognition are needed to establish where a patient is more accurately characterized as having a multimodal disorder of person recognition, whose mechanisms may differ from prosopagnosia. Second, uniform diagnostic criteria are needed. This is particularly an issue for developmental prosopagnosia. Currently, there is no diagnostic consensus: inclusion criteria range from purely self-report measures ${ }^{12,13}$ to various conglomerations of self-report, behavioral tests of face familiarity, and tests of face naming/identification, ${ }^{156,166}$ and few require imaging to exclude brain lesions that would point to an early-onset acquired variant rather than developmental prosopagnosia. Another diagnostic issue that reflects the current lack of definitive genetic or radiologic markers for the developmental form is the challenge of distinguishing subjects with true pathology resulting from aberrant development of face recognition networks from those who are simply at the low end of a spectrum of normal face-processing skill (see Barton and Corrow ${ }^{14}$ for a discussion). 
Nevertheless, it remains a possibility that there is real heterogeneity in developmental prosopagnosia, just as there is in acquired prosopagnosia. This accounts for the current trend to use single-subject methods of analysis, using Crawford's $T$ tests, for example. However, it may be difficult for subtle anomalies to achieve statistical significance at the individual level, as illustrated by recent ERP work. ${ }^{151,152}$ Further work may benefit from the definition of more homogeneous variants, and supplementing the single-subject methods with group analyses on these subgroups. This will necessitate the collection of larger samples of these patients. Such efforts should advance our knowledge of the neuroanatomic and functional origins of these intriguing conditions.

\section{Acknowledgments}

The content is solely the responsibility of the authors and does not necessarily represent the official views of the National Institutes of Health.

\section{Disclosure}

This work was supported by CIHR operating grant (MOP102567) to JB. JB was supported by a Canada Research Chair and the Marianne Koerner Chair in Brain Diseases. SC was supported by National Eye Institute of the National Institutes of Health under award number F32 EY023479-02 and Loan Repayment Program. The authors report no other conflicts of interest in this work.

\section{References}

1. Quaglino A, Borelli G. Emiplegia sinistra con amaurosi-guarigioneperdita totale della percezione dei colori e della memoria della configurazione degli oggetti. [Left hemiplegia with amaurosis-healing-total loss of color perception and the configuration memory of the objects]. Giornale di Oftalmologia Italiano. 1867;10:106-117. Italian.

2. Della Sala S, Young AW. Quaglino's 1867 case of prosopagnosia. Cortex. 2003;39(3):533-540.

3. Bodamer J. Die Prosop-Agnosie. [The Prosopagnosic]. Archiv fur Psychiatrie und Nervenkrankheiten. 1947;179:6-53.

4. Barton JJ. Structure and function in acquired prosopagnosia: lessons from a series of 10 patients with brain damage. J Neuropsychol. 2008; 2(Pt 1):197-225.

5. Duchaine B, Nakayama K. Developmental prosopagnosia: a window to content-specific face processing. Curr Opin Neurobiol. 2006;16(2): 166-173.

6. Susilo T, Duchaine B. Advances in developmental prosopagnosia research. Curr Opin Neurobiol. 2013;23(3):423-429.

7. Schmalzl L, Palermo R, Coltheart M. Cognitive heterogeneity in genetically based prosopagnosia: a family study. JNeuropsychol. 2008; 2(1):99-117.

8. Duchaine B, Germine L, Nakayama K. Family resemblance: ten family members with prosopagnosia and within-class object agnosia. Cogn Neuropsychol. 2007;24(4):419-430.

9. Lee Y, Duchaine B, Wilson HR, Nakayama K. Three cases of developmental prosopagnosia from one family: detailed neuropsychological and psychophysical investigation of face processing. Cortex. 2010;46(8): 949-964.
10. Wilmer JB, Germine L, Chabris CF, et al. Human face recognition ability is specific and highly heritable. Proc Natl Acad Sci USA. 2010;107(11): 5238-5241.

11. Zhu Q, Song Y, Hu S, et al. Heritability of the specific cognitive ability of face perception. Curr Biol. 2010;20(2):137-142.

12. Kennerknecht I, Grueter T, Welling B, et al. First report of prevalence of non-syndromic hereditary prosopagnosia (HPA). Am JMed Genet A. 2006;140(15):1617-1622.

13. Kennerknecht I, Ho NY, Wong VC. Prevalence of hereditary prosopagnosia (HPA) in Hong Kong Chinese population. Am J Med Genet A. 2008;146A(22):2863-2870.

14. Barton JJ, Corrow SL. The problem of being bad at faces. Neuropsychologia. 2016;89:119-124.

15. Yardley L, McDermott L, Pisarski S, Duchaine B, Nakayama K. Psychosocial consequences of developmental prosopagnosia: a problem of recognition. J Psychosom Res. 2008;65(5):445-451.

16. Dalrymple KA, Fletcher K, Corrow S, et al. "A room full of strangers every day": the psychosocial impact of developmental prosopagnosia on children and their families. J Psychosom Res. 2014;77:144-150.

17. Bruce V, Young A. Understanding face recognition. Br J Psychol. 1986;77(Pt 3):305-327.

18. Schweinberger SR, Burton AM. Covert recognition and the neural system for face processing. Cortex. 2003;39(1):9-30.

19. Barton JJ, Corrow SL. Recognizing and identifying people: a neuropsychological review. Cortex. 2016;75:132-150.

20. Gainotti G. Cognitive models of familiar people recognition and hemispheric asymmetries. Front Biosci (Elite Ed). 2014;6:148-158.

21. Farah MJ, O'Reilly RC, Vecera SP. Dissociated overt and covert recognition as an emergent property of a lesioned neural network. Psychol Rev. 1993;100(4):571-588.

22. Belin P, Fecteau S, Bédard C. Thinking the voice: neural correlates of voice perception. Trends Cogn Sci. 2004;8(3):129-135.

23. Ellis HD, Jones DM, Mosdell N. Intra- and inter-modal repetition priming of familiar faces and voices. Br J Psychol. 1997;88(Pt 1):143-156.

24. Burton AM, Bruce V. I recognize your face but I can't remember your name: a simple explanation? Br J Psychol. 1992;83(Pt 1):45-60.

25. Bredart S, Valentine T, Calder A, Gassi L. An interactive activation model of face naming. QJ Exp Psychol A. 1995;48(2):466-486.

26. De Renzi E, Faglioni P, Grossi D, Nichelli P. Apperceptive and associative forms of prosopagnosia. Cortex. 1991;27(2):213-221.

27. Busigny T, Van Belle G, Jemel B, Hosein A, Joubert S, Rossion B. Facespecific impairment in holistic perception following focal lesion of the right anterior temporal lobe. Neuropsychologia. 2014;56:312-333.

28. Busigny T, Joubert S, Felician O, Ceccaldi M, Rossion B. Holistic perception of the individual face is specific and necessary: evidence from an extensive case study of acquired prosopagnosia. Neuropsychologia. 2010;48(14):4057-4092.

29. White D, Rivolta D, Burton AM, Al-Janabi S, Palermo R. Face matching impairment in developmental prosopagnosia. Q J Exp Psychol. Epub 2016 April 22.

30. Barton JJ, Zhao J, Keenan JP. Perception of global facial geometry in the inversion effect and prosopagnosia. Neuropsychologia. 2003;41(12):1703-1711.

31. Duchaine BC, Nakayama K. Developmental prosopagnosia and the benton facial recognition test. Neurology. 2004;62(7):1219-1220.

32. Duchaine BC, Weidenfeld A. An evaluation of two commonly used tests of unfamiliar face recognition. Neuropsychologia. 2003;41(6):713-720.

33. Duchaine B, Nakayama K. The Cambridge Face Memory Test: results from neurologically intact individuals and an investigation of its validity using inverted stimuli and prosopagnosic participants. Neuropsychologia. 2006;44(4):576-585.

34. Esins J, Schultz J, Stemper C, Kennerknecht I, Bülthoff I. Face perception and test reliabilities in congenital prosopagnosia in seven tests. Iperception. 2016;7(1):1-37.

35. McKone E, Stokes S, Liu J, et al. A robust method of measuring other-race and other-ethnicity effects: the Cambridge Face Memory Test format. PLoS One. 2012;7(10):e47956. 
36. McKone E, Hall A, Pidcock M, et al. Face ethnicity and measurement reliability affect face recognition performance in developmental prosopagnosia: evidence from the Cambridge Face Memory TestAustralian. Cogn Neuropsychol. 2011;28(2):109-146.

37. Croydon A, Pimperton H, Ewing L, Duchaine BC, Pellicano E. The Cambridge Face Memory Test for Children (CFMT-C): a new tool for measuring face recognition skills in childhood. Neuropsychologia. 2014;62:60-67.

38. Dalrymple K, Gomez J, Duchaine B. CFMT-Kids: a new test of face memory for children. JVis. 2012;12(9):492.

39. Duchaine B, Yovel G, Nakayama K. No global processing deficit in the Navon task in 14 developmental prosopagnosics. Soc Cogn Affect Neurosci. 2007;2:104-113.

40. Burton A, White D, McNeill A. The Glasgow Face Matching Test. Behav Res Methods. 2010;42(1):286-291.

41. Dalrymple KA, Garrido L, Duchaine B. Dissociation between face perception and face memory in adults, but not children, with developmental prosopagnosia. Dev Cogn Neurosci. 2014;10:10-20.

42. Shah P, Gaule A, Sowden S, Bird G, Cook R. The 20-item prosopagnosia index (PI20): a self-report instrument for identifying developmental prosopagnosia. R Soc Open Sci. 2015;2(6):140343.

43. Barnes CS, De l'Aune W, Schuchard RA. A test of face discrimination ability in aging and vision loss. Optom Vis Sci. 2011;88(2):188-199.

44. Barton JJ, Hanif H, Ashraf S. Relating visual to verbal semantic knowledge: the evaluation of object recognition in prosopagnosia. Brain. 2009;132(Pt 12):3456-3466.

45. Barton JJ, Cherkasova MV, Hefter R, Cox TA, O’Connor M, Manoach DS. Are patients with social developmental disorders prosopagnosic? perceptual heterogeneity in the asperger and socio-emotional processing disorders. Brain. 2004;127(Pt 8):1706-1716.

46. Weigelt S, Koldewyn K, Kanwisher N. Face identity recognition in autism spectrum disorders: a review of behavioral studies. Neurosci Biobehav Rev. 2012;36(3):1060-1084.

47. Duchaine B, Murray H, Turner M, White S, Garrido L. Normal social cognition in developmental prosopagnosia. Cogn Neuropsychol. 2009;26(7):620-634.

48. Wilson CE, Palermo R, Schmalzl L, Brock J. Specificity of impaired facial identity recognition in children with suspected developmental prosopagnosia. Cogn Neuropsychol. 2010;27(1):30-45.

49. Hong D, Scaletta Kent J, Kesler S. Cognitive profile of turner syndrome. Dev Disabil Res Rev. 2009;15(4):270-278.

50. Frith CD, Stevens M, Johnstone EC, Owens DG, Crow TJ. Integration of schematic faces and other complex objects in schizophrenia. JNerv Ment Dis. 1983;171(1):34-39.

51. Archer J, Hay DC, Young AW. Face processing in psychiatric conditions. Br J Clin Psychol. 1992;31(Pt 1):45-61.

52. Roudier M, Marcie P, Grancher AS, Tzortzis C, Starkstein S, Boller F. Discrimination of facial identity and of emotions in Alzheimer's disease. J Neurol Sci. 1998;154(2):151-158.

53. Bäckman L, Herlitz A. The relationship between prior knowledge and face recognition memory in normal aging and Alzheimer's disease. $J$ Gerontol. 1990;45(3):P94-P100.

54. Hodges JR, Salmon DP, Butters N. Recognition and naming of famous faces in Alzheimer's disease: a cognitive analysis. Neuropsychologia. 1993;31(8):775-788.

55. Dewick HC, Hanley JR, Davies AD, Playfer J, Turnbull C. Perception and memory for faces in Parkinson's disease. Neuropsychologia. 1991; 29(8):785-802.

56. Dalrymple KA, Palermo R. Guidelines for studying developmental prosopagnosia in adults and children. Wiley Interdiscip Rev Cogn Sci. 2016;7(1):73-87.

57. Diamond R, Carey S. Why faces are and are not special: an effect of expertise. J Exp Psychol Gen. 1986;115(2):107-117.

58. Gauthier I, Skudlarski P, Gore JC, Anderson AW. Expertise for cars and birds recruits brain areas involved in face recognition. Nat Neurosci. 2000;3(2):191-197.

59. Xu Y, Liu J, Kanwisher N. The M170 is selective for faces, not for expertise. Neuropsychologia. 2005;43:588-597.
60. Behrmann M, Plaut DC. Distributed circuits, not circumscribed centers, mediate visual recognition. Trends Cogn Sci. 2013;17(5):210-219.

61. Behrmann M, Plaut DC. Bilateral hemispheric processing of words and faces: evidence from word impairments in prosopagnosia and face impairments in pure alexia. Cereb Cortex. 2014;24(24):1102-1118.

62. Liu R, Pancaroglu R, Hills CS, Duchaine B, Barton JJ. Voice recognition in face-blind patients. Cereb Cortex. 2016;26(4):1473-1487.

63. Neuner F, Schweinberger SR. Neuropsychological impairments in the recognition of faces, voices, and personal names. Brain Cogn. 2000;44(3):342-366.

64. Grill-Spector K. The neural basis of object perception. Curr Opin Neurobiol. 2003;13:159-166.

65. Haxby J, Gobbini M. Distributed neural systems for face perception. In: Calder A, Rhodes G, Johnson M, Haxby J, editors. The Oxford Handbook of Face Perception. Oxford, United Kingdom: Oxford University Press; 2011:93-110.

66. Haxby JV, Gobbini MI, Furey ML, Ishai A, Schouten JL, Pietrini P. Distributed and overlapping representations of faces and objects in ventral temporal cortex. Science. 2001;293(5539):2425-2430.

67. Kanwisher N. Domain specificity in face perception. Nat Neurosci. 2000;3(8):759-763.

68. Pitcher D, Charles L, Devlin JT, Walsh V, Duchaine B. Triple dissociation of faces, bodies, and objects in extrastriate cortex. Curr Biol. 2009;19(4):319-324

69. Farah MJ, Levinson KL, Klein KL. Face perception and within-category discrimination in prosopagnosia. Neuropsychologia. 1995;33(6):661-674.

70. Susilo T, Yovel G, Barton JJ, Duchaine B. Face perception is categoryspecific: evidence from normal body perception in acquired prosopagnosia. Cognition. 2013;129(1):88-94.

71. Rezlescu C, Pitcher D, Duchaine B. Acquired prosopagnosia with spared within-class object recognition but impaired recognition of degraded basic-level objects. Cogn Neuropsychol. 2012;29(4):325-347.

72. Rezlescu C, Barton JJ, Pitcher D, Duchaine B. Normal acquisition of expertise with greebles in two cases of acquired prosopagnosia. Proc Natl Acad Sci U S A. 2014;111(14):5123-5128.

73. Riddoch MJ, Johnston RA, Bracewell RM, Boutsen L, Humphreys GW. Are faces special? a case of pure prosopagnosia. Cogn Neuropsychol. 2008;25(1):3-26

74. McNeil JE, Warrington EK. Prosopagnosia: a face-specific disorder. QJ Exp Psychol A. 1993;46(1):1-10.

75. Farah MJ, Wilson KD, Drain HM, Tanaka JR. The inverted face inversion effect in prosopagnosia: evidence for mandatory, face-specific perceptual mechanisms. Vision Res. 1995;35(14):2089-2093.

76. Henke K, Schweinberger SR, Grigo A, Klos T, Sommer W. Specificity of face recognition: recognition of exemplars of non-face objects in prosopagnosia. Cortex. 1998;34(2):289-296.

77. Gauthier I, Berhmann M, Tarr MJ. Can face recognition really be dissociated from object recognition? J Cogn Neurosci. 1999;11(4):349-370.

78. Davies-Thompson J, Pancaroglu R, Barton J. Acquired prosopagnosia: structural basis and processing impairments. Front Biosci (Elite Ed). 2014;6:159-174.

79. Duchaine B, Nakayama K. Dissociations of face and object recognition in developmental prosopagnosia. J Cogn Neurosci. 2005;17(2): 249-261.

80. Garrido L, Furl N, Draganski B, et al. Voxel-based morphometry reveals reduced grey matter volume in the temporal cortex of developmental prosopagnosics. Brain. 2009;132(Pt 12):3443-3455.

81. Susilo T, McKone E, Dennett H, et al. Face recognition impairments despite normal holistic processing and face space coding: evidence from a case of developmental prosopagnosia. Cogn Neuropsychol. 2010;27(8):636-664.

82. Tree J, Wilkie J. Face and object imagery in congenital prosopagnosia: a case series. Cortex. 2010;46(9):1189-1198.

83. Duchaine B, Yovel G, Butterworth E, Nakayama K. Prosopagnosia as an impairment to face-specific mechanisms: elimination of the alternative hypotheses in a developmental case. Cogn Neuropsychol. 2006;23(5):714-747. 
84. Nunn J, Postma P, Pearson R. Developmental prosopagnosia: should it be taken at face value? Neurocase. 2001;7(1):15-27.

85. Behrmann M, Avidan G. Congenital prosopagnosia: face-blind from birth. Trends Cogn Sci. 2005;9(4):180-187.

86. De Haan EH, Campbell R. A fifteen year follow-up of a case of developmental prosopagnosia. Cortex. 1991;27(4):489-509.

87. Duchaine BC, Nieminen-von Wendt T, New J, Kulomaki T. Dissociations of visual recognition in a developmental agnosic: evidence for separate developmental processes. Neurocase. 2003;9(5):380-389.

88. Duchaine BC, Parker H, Nakayama K. Normal recognition of emotion in a prosopagnosic. Perception. 2003;32(7):827-838.

89. Jones RD, Tranel D. Severe developmental prosopagnosia in a child with superior intellect. J Clin Exp Neuropsychol. 2001;23(3):265-273.

90. Ariel R, Sadeh M. Congenital visual agnosia and prosopagnosia in a child. Cortex. 1996;12:76-82.

91. McConachie HR. Developmental prosopagnosia. A single case report. Cortex. 1976;12(1):76-82.

92. Brunsdon R, Coltheart M, Nickels L, Joy P. Developmental prosopagnosia: a case analysis and treatment study. Cogn Neuropsychol. 2006;23(6):822-840.

93. Dalrymple KA, Elison JT, Duchaine B. Face-specific and domaingeneral visual processing deficits in children with developmental prosopagnosia. Q J Exp Psychol (Hove). Epub 2016 May 4.

94. Dennett HW, McKone E, Tavashmi R, et al. The Cambridge Car Memory Test: a task matched in format to the Cambridge Face Memory Test, with norms, reliability, sex differences, dissociations from face memory, and expertise effects. Behav Res Methods. 2012;44(2):587-605.

95. Nestor A, Behrmann M, Plaut DC. The neural basis of visual word form processing: a multivariate investigation. Cereb Cortex. 2013;23(7):1673-1684.

96. Dundas EM, Plaut DC, Behrmann M. The joint development of hemispheric lateralization for words and faces. J Exp Psychol Gen. 2013;142(2):348-358.

97. Dehaene S, Pegado F, Braga LW, et al. How learning to read changes the cortical networks for vision and language. Science. 2010;330(6009): $1359-1364$.

98. Marotta JJ, McKeeff TJ, Behrmann M. The effects of rotation and inversion on face processing in prosopagnosia. Cogn Neuropsychol. 2002;19(1):31-47.

99. Susilo T, Wright V, Tree JJ, Duchaine B. Acquired prosopagnosia without word recognition deficits. Cogn Neuropsychol. 2015;32(6):321-339.

100. Hills CS, Pancaroglu R, Duchaine B, Barton JJ. Word and text processing in acquired prosopagnosia. Ann Neurol. 2015;78(2):258-271.

101. Rubino C, Corrow SL, Corrow JC, Duchaine B, Barton JJ. Word and text processing in developmental prosopagnosia. Cogn Neuropsychol. 2016;33(5-6).

102. Hoover AE, Demonet JF, Steeves JK. Superior voice recognition in a patient with acquired prosopagnosia and object agnosia. Neuropsychologia. 2010;48(13):3725-3732.

103. Liu RR, Corrow SL, Pancaroglu R, Duchaine B, Barton JJ. The processing of voice identity in developmental prosopagnosia. Cortex. 2015; 71:390-397.

104. Moroz D, Corrow SL, Corrow JC, Barton AR, Duchaine B, Barton JJ. Localization and patterns of Cerebral dyschromatopsia: a study of subjects with prospagnosia. Neuropsychologia. 2016;89:153-160.

105. Bouvier SE, Engel SA. Behavioral deficits and cortical damage loci in cerebral achromatopsia. Cereb Cortex. 2006;16(2):183-191.

106. Schmidt D. Neuro-ophthalmological findings in patients with acquired prosopagnosia. Graefes Arch Clin Exp Ophthalmol. 2015;253(3): 333-334.

107. Epstein R, Kanwisher N. A cortical representation of the local visual environment. Nature. 1998;392(6676):598-601.

108. Kanwisher N, McDermott J, Chun MM. The fusiform face area: a module in human extrastriate cortex specialized for face perception. J Neurosci. 1997;17(11):4302-4311.

109. Temple CM. Developmental memory impairment: faces and patterns. In: Campbell R, editor. Mental Lives: Case Studies in Cognition. Oxford, United Kingdom: Blackwell; 1992:199-215.
110. Duchaine BC. Developmental prosopagnosia with normal configural processing. Neuroreport. 2000;11(1):79-83.

111. Bentin S, Deouell LY, Soroker N. Selective visual streaming in face recognition: evidence from developmental prosopagnosia. Neuroreport. 1999;10(4):823-827.

112. Corrow JC, Corrow SL, Lee E, et al. Getting lost: topographic skills in acquired and developmental prosopagnosia. Cortex. 2016;76: 89-103.

113. Gobbini MI, Haxby JV. Neural systems for recognition of familiar faces. Neuropsychologia. 2007;45(1):32-41.

114. Haxby JV, Hoffman EA, Gobbini MI. The distributed human neural system for face perception. Trends Cogn Sci. 2000;4(6):223-233.

115. Jonas J, Rossion B, Brissart H, et al. Beyond the core face-processing network: intracerebral stimulation of a face-selective area in the right anterior fusiform gyrus elicits transient prosopagnosia. Cortex. 2015;72:140-155.

116. Damasio AR, Tranel D, Damasio H. Face agnosia and the neural substrates of memory. Annu Rev Neurosci. 1990;13:89-109.

117. Damasio AR, Damasio H, Van Hoesen GW. Prosopagnosia: anatomic basis and behavioral mechanisms. Neurology. 1982;32(4):331-341.

118. De Renzi E. Prosopagnosia in two patients with CT scan evidence of damage confined to the right hemisphere. Neuropsychologia. 1986;24(3):385-389.

119. Mattson AJ, Levin HS, Grafman J. A case of prosopagnosia following moderate closed head injury with left hemisphere focal lesion. Cortex. 2000;36(1):125-137.

120. Tzavaras A, Merienne L, Masure MC. Prosopagnosie, amnésie et troubles du langage par lésion temporale gauche chez un sujet gaucher [Prosopagnosia, amnesia and language disorders by left temporal lesion in a left-handed subject]. Encephale. 1973;62(4):382-394. French.

121. Barton JJ. Prosopagnosia associated with a left occipitotemporal lesion. Neuropsychologia. 2008;46(8):2214-2224.

122. Yang H, Susilo T, Duchaine B. The anterior temporal face area contains invariant representations of face identity that can persist despite the loss of right FFA and OFA. Cereb Cortex. 2016:26(3): 1096-1107.

123. Barton JJ, Press DZ, Keenan JP, O'Connor M. Lesions of the fusiform face area impair perception of facial configuration in prosopagnosia. Neurology. 2002;58(1):71-78.

124. Kanwisher N, Barton J. The functional architecture of the face system: Integrating evidence from fMRI and patient studies. In: Rhodes G, Calder A, Johnson M, Haxby JV, editors. Oxford Handbook of Face Perception. Oxford: United Kingdom; 2011.

125. Barton JJ, Cherkasova M. Face imagery and its relation to perception and covert recognition in prosopagnosia. Neurology. 2003;61(2): 220-225.

126. Hasson U, Avidan G, Deouell LY, Bentin S, Malach R. Face-selective activation in a congenital prosopagnosic subject. J Cogn Neurosci. 2003; 15(3):419-431.

127. Avidan G, Hasson U, Malach R, Behrmann M. Detailed exploration of face-related processing in congenital prosopagnosia: 2. functional neuroimagining findings. $J$ Cogn Neurosci. 2005;17(7):1150-1167.

128. Hadjikhani N, de Gelder B. Neural basis of prosopagnosia: an fMRI study. Hum Brain Mapp. 2002;16(3):176-182.

129. Bentin S, DeGutis JM, D'Esposito M, Robertson LC. Too many trees to see the forest: performance, event-related potential, and functional magnetic resonance imaging manifestations of integrative congenital prosopagnosia. J Cogn Neurosci. 2007;19(1):132-146.

130. Furl N, Garrido L, Dolan RJ, Driver J, Duchaine B. Fusiform gyrus face selectivity relates to individual differences in facial recognition ability. J Cogn Neurosci. 2011;23(7):1723-1740.

131. Zhang J, Liu J, Xu Y. Neural decoding reveals impaired face configural processing in the right fusiform face area of individuals with developmental prosopagnosia. J Neurosci. 2015;35(4):1539-1548.

132. Gomez J, Pestilli F, Witthoft N, et al. Functionally defined white matter reveals segregated pathways in human ventral temporal cortex associated with category-specific processing. Neuron. 2015;85(1): 216-227. 
133. Song S, Garrido L, Nagy Z, et al. Local but not long-range microstructural differences of the ventral temporal cortex in developmental prosopagnosia. Neuropsychologia. 2015;78:195-206.

134. Avidan G, Tanzer M, Hadj-Bouziane F, Liu N, Ungerleider LG, Behrmann $\mathrm{M}$. Selective dissociation between core and extended regions of the face processing network in congenital prosopagnosia. Cereb Cortex. 2014;24(6):1565-1578.

135. Behrmann M, Avidan G, Gao F, Black S. Structural imaging reveals anatomical alterations in inferotemporal cortex in congenital prosopagnosia. Cereb Cortex. 2007;17(10):2354-2363.

136. Avidan G, Behrmann M. Functional MRI reveals compromised neural integrity of the face processing network in congenital prosopagnosia. Curr Biol. 2009;19(13):1146-1150.

137. Thomas C, Avidan G, Humphreys K, Jung KJ, Gao F, Behrmann M. Reduced structural connectivity in ventral visual cortex in congenital prosopagnosia. Nat Neurosci. 2009;12(1):29-31.

138. Bentin S, Allison T, Puce A, Perez E, McCarthy G. Electrophysiological studies of face perception in humans. $J$ Cogn Neurosci. 1996;8(6):551-565.

139. Towler J, Eimer M. Electrophysiological studies of face processing in developmental prosopagnosia: neuropsychological and neurodevelopmental perspectives. Cogn Neuropsychol. 2012;29(5-6):503-529.

140. Eimer M. The face-sensitive N170 component of the event-related brain potential. In: Calder AJ, Rhodes G, Johnson M, Haxby J, editors The Oxford Handbook of Face Perception. Oxford, United Kingdom: Oxford University Press; 2011:329-344.

141. Tanaka JW, Curran T, Porterfield AL, Collins D. Activation of preexisting and acquired face representations: the N250 event-related potential as an index of face familiarity. J Cogn Neurosci. 2006;18(9):1488-1497.

142. Gosling A, Eimer M. An event-related brain potential study of explicit face recognition. Neuropsychologia. 2011;49(9):2736-2745.

143. Eimer M. Event-related brain potentials distinguish processing stages involved in face perception and recognition. Clin Neurophysiol. 2000;111(4):694-705.

144. Dalrymple KA, Oruc I, Duchaine B, et al. The anatomic basis of the right face-selective N170 IN acquired prosopagnosia: a combined ERP/fMRI study. Neuropsychologia. 2011;49(9):2553-2563.

145. Prieto EA, Caharel S, Henson R, Rossion B. Early (N170/M170) face-sensitivity despite right lateral occipital brain damage in acquired prosopagnosia. Front Human Neurosci. 2011;5:138.

146. Eimer M, McCarthy RA. Prosopagnosia and structural encoding of faces: evidence from event-related potentials. Neuroreport. 1999; 10(2):255-259.

147. Harris AM, Duchaine BC, Nakayama K. Normal and abnormal face selectivity of the M170 response in developmental prosopagnosics. Neuropsychologia. 2005;43(14):2125-2136.

148. Rivolta D, Palermo R, Schmalzl L, Williams MA. Investigating the features of the M170 in congenital prosopagnosia. Front Human Neurosci. 2012;6:45.

149. de Gelder B, Stekelenburg JJ. Naso-temporal asymmetry of the N170 for processing faces in normal viewers but not in developmental prosopagnosia. Neurosci Lett. 2005;376(1):40-45.
150. Kress T, Daum I. Event-related potentials reflect impaired face recognition in patients with congenital prosopagnosia. Neurosci Lett. 2003;352(2):133-136.

151. Lueschow A, Weber JE, Carbon C-C, et al. The $170 \mathrm{~ms}$ response to faces as measured by MEG (M170) is consistently altered in congenital prosopagnosia. PLoS One. 2015;10(9):e0137624.

152. Towler J, Gosling A, Duchaine B, Eimer M. The face-sensitive N170 component in developmental prosopagnosia. Neuropsychologia. 2012;50(14):3588-3599.

153. Righart R, de Gelder B. Impaired face and body perception in developmental prosopagnosia. Proc Natl Acad Sci U S A. 2007;104(43): 17234-17238.

154. Minnebusch DA, Suchan B, Ramon M, Daum I. Event-related potentials reflect heterogeneity of developmental prosopagnosia. Eur $J$ Neurosci. 2007;25(7):2234-2247.

155. Eimer M, Gosling A, Duchaine B. Electrophysiological markers of covert face recognition in developmental prosopagnosia. Brain. 2012;135(2):542-554.

156. Parketny J, Towler J, Eimer M. The activation of visual face memory and explicit face recognition are delayed in developmental prosopagnosia. Neuropsychologia. 2015;75:538-547.

157. Towler J, Fisher K, Eimer M. The cognitive and neural basis of developmental prosopagnosia. Q J Exp Psychol (Hove). 2016:1-29.

158. Bate S, Bennetts RJ. The rehabilitation of face recognition impairments: a critical review and future directions. Front Hum Neurosci. 2014;8:491.

159. DeGutis JM, Chiu C, Grosso ME, Cohan S. Face processing improvements in prosopagnosia: successes and failures over the last 50 years Front Human Neurosci. 2014;8:561.

160. Ellis HD, Young A. Training in face-processing skills for a child with acquired prosopagnosia. Dev Neuropsychol. 1988;4(4):283-294.

161. DeGutis J, Cohan S, Kahn DA, Aguirre GK, Nakayama K. Facial expression training improves emotion recognition and changes neural tuning in a patient with acquired emotion recognition deficits and prosopagnosia. J Vis. 2013;13(9):993-993.

162. Davies-Thompson J, Fletcher K, Hills C, Corrow S, Pancaroglu R, Barton JJS. Perceptual training of faces in rehabilitation of acquired prosopagnosia. Paper presented at: 38th European Conference on Visual Percpetion; August 23-27; 2015; Liverpool, United Kingdom.

163. DeGutis JM, Bentin S, Robertson LC, D'Esposito M. Functional plasticity in ventral temporal cortex following cognitive rehabilitation of a congenital prosopagnosic. J Cogn Neurosci. 2007;19(11): 1790-1802.

164. DeGutis J, Cohan S, Nakayama K. Holistic face training enhances face processing in developmental prosopagnosia. Brain. 2014;137(Pt 6): 1781-1798.

165. Bate S, Cook SJ, Duchaine B, Tree JJ, Burns EJ, Hodgson TL. Intranasal inhalation of oxytocin improves face processing in developmental prosopagnosia. Cortex. 2014;50:55-63.

166. Towler J, Parketny J, Eimer M. Perceptual face processing in developmental prosopagnosia is not sensitive to the canonical location of face parts. Cortex. 2016;74:53-66.
Eye and Brain

\section{Publish your work in this journal}

Eye and Brain is an international, peer-reviewed, open access journal focusing on clinical and experimental research in the field of neuroophthalmology. All aspects of patient care are addressed within the journal as well as basic research. Papers covering original research, basic science, clinical and epidemiological studies, reviews and evaluations,

Submit your manuscript here: https://www.dovepress.com/eye-and-brain-journal guidelines, expert opinion and commentary, case reports and extended reports are welcome. The manuscript management system is completely online and includes a very quick and fair peer-review system, which is all easy to use. Visit http://www.dovepress.com/testimonials.php to read real quotes from published authors. 